\title{
Designing an Online Course to Teach Anaphora in Foreign Languages
}

\author{
Amanda Maraschin Bruscato and Jorge Baptista \\ ${ }^{1}$ Faculty of Human and Social Sciences, University of Algarve, Portugal \\ ${ }^{2}$ INESC-ID Lisboa/HLT, Portugal \\ E-mail: amandabruscato@gmail.com
}

Cite this article as: Bruscato, A. M., \& Baptista, J. (2021). Designing an Online Course to Teach Anaphora in Foreign Languages. International Journal of Second and Foreign Language Education, 1(1), 1-9. https://doi.org/10.33422/ijsfle.v1i1.58

\begin{abstract}
This paper presents the designing of an online course to teach anaphora in English and Spanish as foreign languages. Anaphora is a discursive mechanism that contributes to textual cohesion. Instead of repeating the same nouns in their texts, speakers can use different pronouns or even ellipsis to improve communication. Each language has its own anaphoric system, which can be very distinct from null-subject languages, such as Spanish, to non-null-subject languages, such as English. Focusing on this topic, a two-week course was designed and taught in 2020 at the Federal University of Rio Grande do Sul (Brazil) and at the University of Algarve (Portugal) to language undergraduate students. The first lesson was an introduction to the concepts of cohesion, anaphora, and the pronominal system in the target language. These topics were further explained in the second lesson, which was also about ambiguity. The activities included: educational videos; tools for corpus analysis and coreference resolution; discussion forums; short answer, matching, and multiple-choice exercises; hyperlinks to more videos, texts, and exercises. Students' knowledge of anaphora was assessed in a pre-test and in three post-tests (discussed in another article), and the results were compared between experimental and control groups. The teaching module improved learners' comprehension of written texts and could be adapted to teach anaphora in other languages.
\end{abstract}

Keywords: anaphora resolution, EFL, e-learning, SFL, textual cohesion

\section{Introduction}

In the beginning of 2020, because of the Covid-19 pandemic, universities around the world had to temporarily suspend their in-person classes and move the learning environment to online platforms. Although the platforms already existed, many professors were not used to teaching through them (Marinoni, Van't Land \& Jensen, 2020).

While faculties were organizing their new distance programmes, we have decided to offer a short online course to language undergraduate students in Brazil and in Portugal. The programme was designed to teach anaphora to intermediate and advanced learners of English and Spanish at the Federal University of Rio Grande do Sul and at the University of Algarve.

The understanding of anaphora as a cohesive device is indispensable to language learning and is assessed to measure language proficiency (Bruscato \& Baptista, 2021c). An example of an online course designed to teach it, in Chinese reading, is described by Li (2014). The author used a three-element pedagogy consisting of scaffolding, engaging, and reflecting to teach reference tracking skills to English native speakers.

(C) The Author(s). 2021 Open Access. This article is distributed under the terms of the Creative Commons Attribution 4.0 International License, which permits unrestricted use, distribution, and redistribution in any medium, provided that the original author(s) and source are credited. 
By offering the course, our plan was also to collect data for our research. Inspired by Li (2014) and Offir, Lev, and Bezalel (2008), we wanted to investigate the effects of the distance learning modality (synchronous or asynchronous) on students' learning outcomes. Thus, there were three groups of participants: one that had synchronous lessons, one that had asynchronous lessons, and another that had no lesson (the control group). Results from this study are analysed in another paper (Bruscato \& Baptista, 2021b) and will not be discussed here.

The aim of this paper is to present the designing of an online course to teach anaphora in foreign languages. We have used the universities' online learning platform (Moodle) for the two lessons and the four written tests (one pre-test and three post-tests). Since the lesson plans for the synchronous and asynchronous groups were practically the same, with the main difference that the first one did the activities during videoconferences, we have decided to focus here on the asynchronous course. Besides educational videos, there were activities involving corpus analysis and coreference resolution tools; discussion forums; short answer, matching, and multiple-choice exercises; and hyperlinks were provided to more videos, texts, and exercises.

In the next sections, we will explain the methods adopted and the choices made in the designing of the course.

\section{Materials and Methods}

We have decided to offer an online course to teach anaphora in English and Spanish to Brazilian and Portuguese undergraduate students because we have noticed that, when learning a language, speakers repeat nouns in their texts instead of using the correct pronouns or ellipsis. After approval from the universities, we have applied an online questionnaire to assess students' linguistic knowledge and motivation to study. With the results in mind, we have defined what participants should be able to do after taking the course. They should be able to:

a) know the importance of anaphora for textual cohesion;

b) identify the different types of anaphora;

c) understand the target language's anaphoric system;

d) find and correct anaphoric errors in texts;

e) recognize and resolve anaphoric ambiguity in texts;

f) choose the appropriate anaphoric expressions for each context;

g) use the basics of corpus analysis and anaphora resolution tools.

After deciding what they should be able to do, we have listed what exactly they needed to learn and what would be the best way to teach them. We have opted for active methodologies (Bonwell \& Eison, 1991), in which students reflect on the concepts, put into practice their learning, and discuss their discoveries with their peers. The main goal was for them to apply the knowledge of anaphora to improve reading and writing in the foreign language. To assess it, they had four written tests (one pre-test and three post-tests), which were like the example below.

Read the beginning of a narrative and correct the mistakes you find, then write an end to the story between 100 and 150 words.

John and Mary were twins and they were only twelve years old when became orphans. Before these misfortune, John and Mary lived with them parents, Joseph and Ana, that loved they very much. They were all happy, until the country declared war. Joseph was sent to fight, and his wife had to take care of the children and the house. One day, a letter from the government arrived. Ana already knew her content: hers husband was dead. The widow became 
herself deeply depressed and could not get out of bed. In despair, John and Mary decided to visit the only neighbour they had (they called her witch) to ask for help.

The tests were designed to evaluate reading and writing in the same activity. The first part of the exercise gave the context to the second part while asking students to analyse and correct the text, something they will probably need to do in their professions. Then, the second part was used to stimulate learners' creativity and writing in the language. At the end of the programme, they were also asked to anonymously evaluate the course on Moodle.

Based on Richards' (2013) backward design to language teaching and on Diamond's (2011, p.10) basic sequence to course design with a learning-centred approach, which starts with the statement of need and the statement of goals before the design of instruction and assessment, we have followed five steps presented as questions in Figure 1:

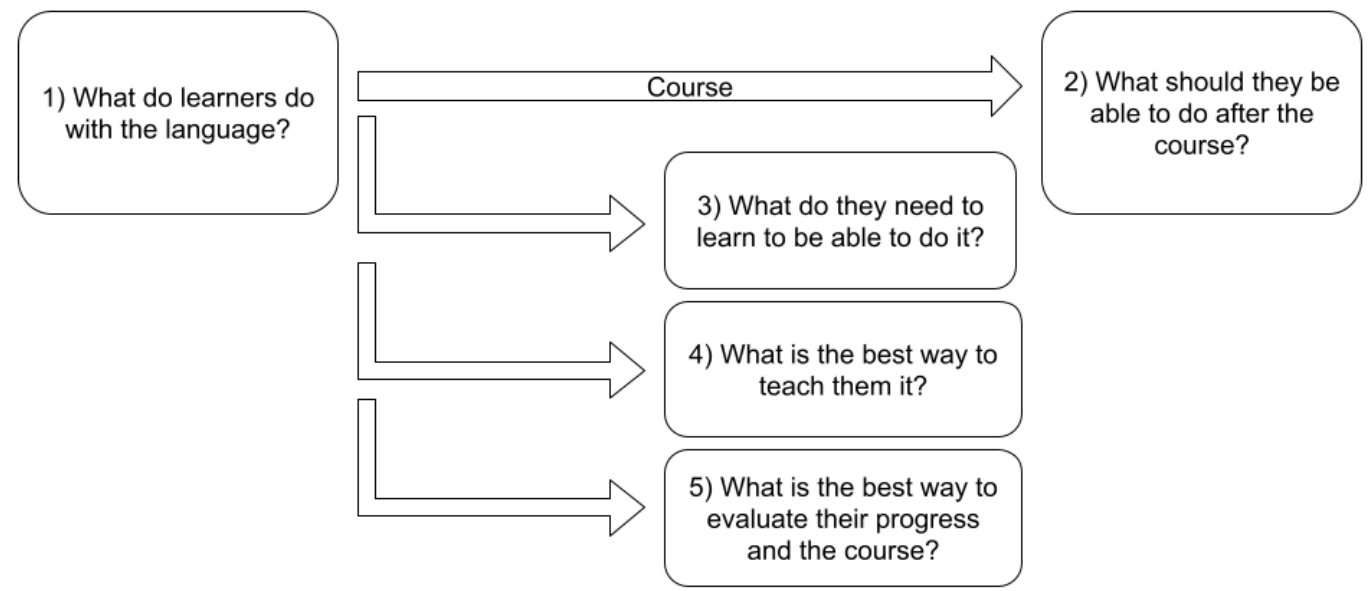

Figure 1. Five steps of language course design

Source: own figure

\section{Results: Course on anaphora}

Anaphora is a discursive mechanism that contributes to textual cohesion (Halliday \& Hasan, 1976). It is a reference device in which an anaphor is used to refer to an antecedent, avoiding its unnecessary repetition, as seen in example (1).

(1) Anna stretches and $\varnothing^{1} /$ she/Anna takes a shower every morning.

Instead of repeating the same words in their texts, speakers can use different pronouns or even ellipsis to improve communication. Although ellipsis is used both in English and Spanish, its rules are not the same. Each language has its own anaphoric system, which is very distinct in null-subject languages, such as Spanish, and in non-null-subject languages, such as English (Chomsky, 1981).

To teach anaphora in English and Spanish, a short online course of two lessons was developed. The first lesson was an introduction to cohesion, anaphora, and the pronominal system in the target language. These concepts were further explained in the second lesson, which also covered ambiguity. Students first practiced their knowledge with sentences, then they had time to reflect on it, discuss with their peers, and finally practice with texts.

The short course focused on this grammatical topic and was designed to involve tasks with authentic texts, apply language analysis tools commonly used by linguists, and encourage interaction through

\footnotetext{
${ }^{1}$ This symbol Ø stands for the ellipsis of an element.
} 
discussion forums. The lessons followed sequences that went from simpler and more controlled to more complex and more open-ended activities, following Graves (2000, p. 136).

The activities were carried out in synchronous and asynchronous lessons. The difference is that, during videoconferences, students did not have the automatic feedback from the computer and had to discuss their findings orally. According to Schwartz (2010, p.15), the human brain cannot sustain a high level of attention for more than 90 minutes, that is why each lesson was planned to have the duration of an hour and a half.

\section{- First lesson}

The first lesson started with a presentation activity that also served as an interactive way to introduce students to anaphora. Initially, learners read two versions of a text in which the teacher presented herself: one with the repetition of the subject pronoun before every verb, and another with ellipsis. Then, they were asked to indicate which version seemed better and read a small explanation justifying the use of ellipsis in coordinate clauses with coreferent subjects. Finally, they presented themselves on the forum.

After this exercise, they watched a 15 minutes talk on anaphora in the target language. Besides having access to the videos, they could also read the PowerPoint presentations and lesson scripts. They learned that anaphora as a figure of speech is the repetition of words to produce a stylistic effect, usually in songs or poems. They were shown how, in other types of text, however, it would be better to use pronouns or ellipsis.

The videos not only introduced learners to cohesion, anaphora, and the language's pronominal system, but they also compared many acceptable and unacceptable sentences involving anaphora, aiming to explain how it would be possible to correct the unacceptable ones. In the end, students were asked to discuss what they have learned (comparing their previous and new knowledge) and share their questions on the forum.

Figure 2 presents some of the slides used in the first lesson. They were used to explain how zero and pronominal anaphora can contribute to textual cohesion by eliminating excessive nominal repetition. The antecedents and anaphors are highlighted with different colours.

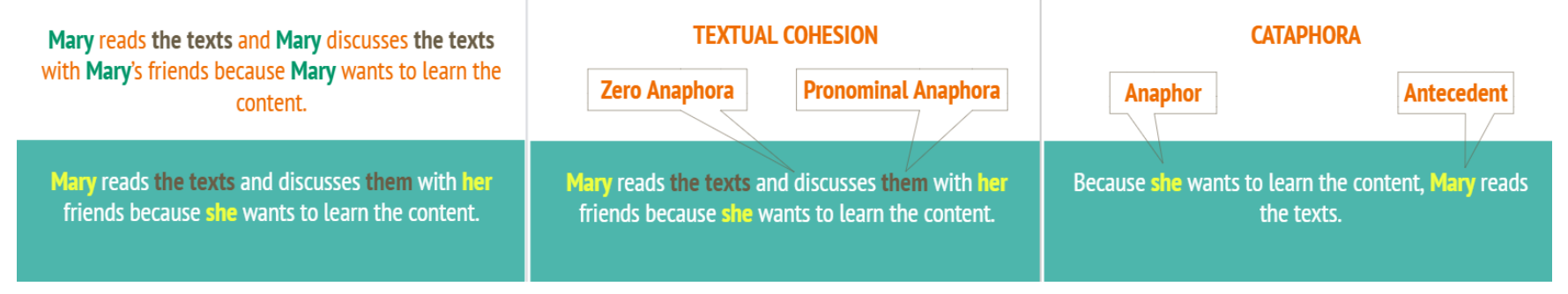

Figure 2. Part of the first lesson on anaphora Source: own figure

The short videos were the only moment of exposition in the lesson. During the rest of the time, learners completed different exercises. They have heard the explanation of the null-subject parameter and were told that, although English is not a null-subject language, speakers use zero anaphora in coordinate clauses with the same subject. To make them reflect on it and check how native speakers behave, they did a corpus-based activity.

Data-driven learning, especially if it requires a hands-on approach (Boulton, 2010), encourages learners to actively discover the language (Johns, 1991). With that in mind, we have instructed students 
on how to use Sketch Engine ${ }^{2}$, a user-friendly tool for corpus analysis. They were asked to search in English or Spanish corpora for sequences formed by a conjunction, a subject pronoun, and a verb; in English, the part-of-speech $(\mathrm{PoS})$ tags used were [tag="CC"][tag="PP"][tag="V.*"]. Then, they were asked to analyse the contexts presented in the first page of the concordances and to compare the results with the search for sequences without the pronoun. They were also encouraged to search for other strings to narrow down or broaden the scope of their search (like [tag="PP"][tag="V.*"] $[\operatorname{tag}=" \mathrm{CC} "][\operatorname{tag}=" \mathrm{PP} "][\mathrm{tag}=" \mathrm{~V} . * "])$, and finally they shared their conclusions and questions on the forum.

Figure 3 presents an example of the results. It shows the concordances of the searched sequences in the English Web 2013 sample corpus, the number of occurrences per million, and the keywords in context. Students analysed whether the pronouns or ellipsis were instances of anaphora and whether a specific context could justify that particular occurrence.

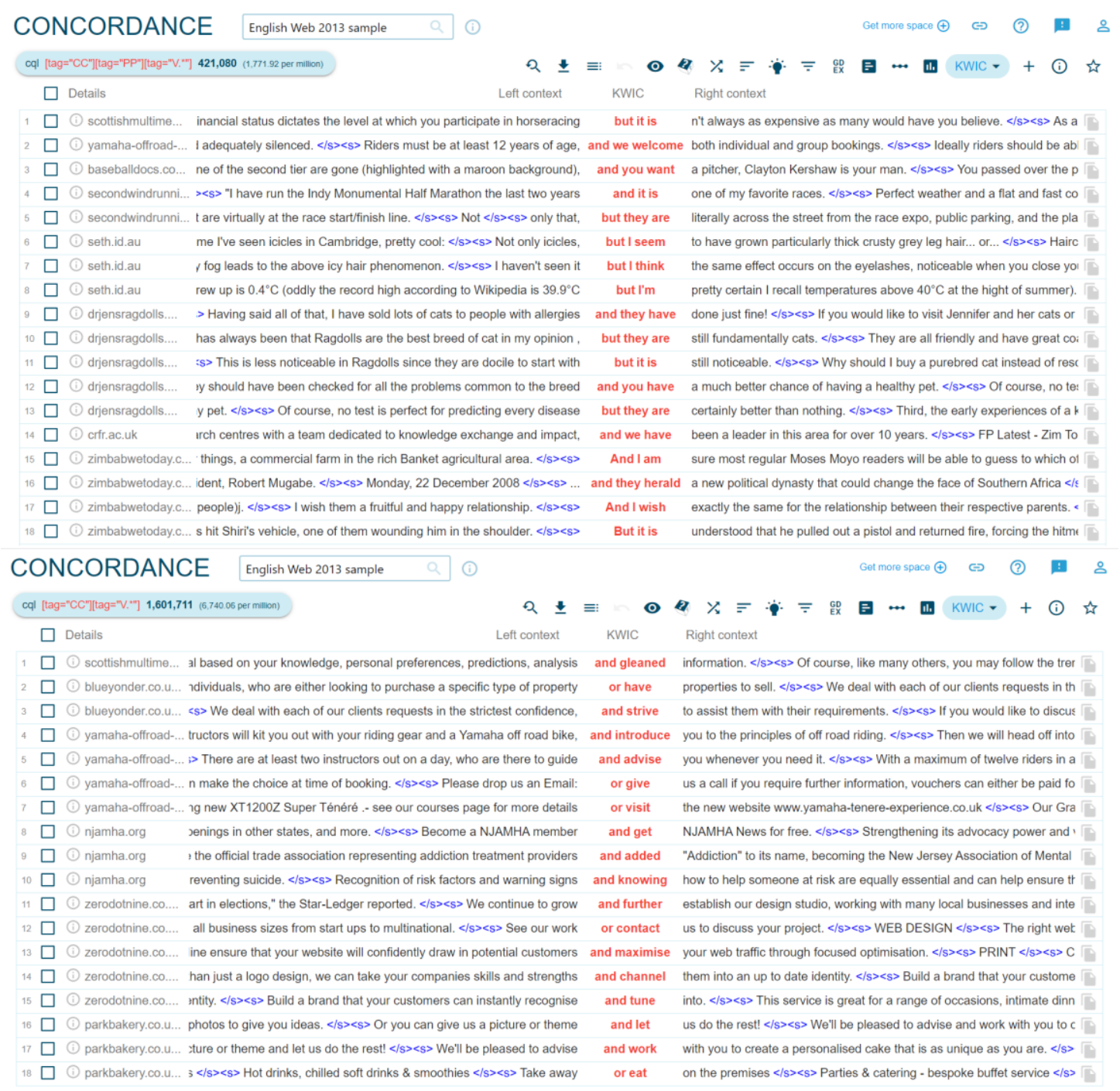

Figure 3. Example of search on Sketch Engine

Source: Sketch Engine

2 https://www.sketchengine.eu/ 
After discussing their findings, learners had to participate in another activity involving pronouns. First, they were asked to complete a sentence with the pronouns in the correct positions. Then, they had to create a similar exercise on the forum and answer one of their classmates'.

Although students had to participate in many forums, they also had many automatic exercises for selfstudy. For example, in the first lesson, they had to choose the right pronouns for 20 sentences. To help them, they had access to a pronoun chart and received automatic feedback with the explanation in case of mistakes.

Finally, the lesson ended with an activity like the one in the test. Students had to read the beginning of a narrative, correct the mistakes they find, and write an end to the story between 100 and 150 words. However, instead of sending it to the teacher, they had to share it on the forum and comment on another text from one of their classmates. They were told to share their impressions on the story, as well as to analyse the use of anaphora in it. The teacher also participated in all the forums.

\section{- Second lesson}

To start the second lesson, learners read the beginning of 12 sentences and were asked to complete them and to discuss their choices on the forum. Each sentence had a plural animated subject, a verb, a plural animated object, and a subordinate conjunction (e.g. Dogs chase postmen, though...). Students were asked to analyse whether their final sentences seemed ambiguous, whether they had decided to retake the subject or the complement of the main clause, and which type of anaphora they had used. They could also choose a new subject for the subordinate clause.

After the first exercise had activated their knowledge on anaphora and ambiguity, they watched a video and read a scientific paper on the topic. For English, Gardelle (2012) was suggested and, for Spanish, Perales and Mayorga (2007). Students could also search for other papers to discuss on the forum. They learned about more complex cases of anaphora, the differences between determinants and pronouns, relative pronouns, and ambiguity. Figure 4 exemplifies an ambiguous sentence discussed in this lesson, for which two possible solutions were given.

\section{$?$ \\ Anna invited Mary over because she didn't want to be alone.}

\section{Anna didn't want to be alone, so she invited Mary over.}

\section{or}

Mary didn't want to be alone, so Anna invited her over.

Figure 4. Example of ambiguous sentence discussed in the second lesson Source: own figure 
Following the discussion forum, learners answered exercises with automatic feedback. They had to correct 10 sentences with anaphoric errors and choose the correct pronouns for 20 other sentences, which were more complex than the ones in the first lesson. For example, they had to choose between object or reflexive pronouns and to select the correct relative pronoun for each sentence.

To finish the lesson, the concept of coreference resolution was introduced, defined and exemplified with authentic texts. Students were asked to (i) read a fable, (ii) think about the story and the use of anaphora in the text, (iii) identify the coreferences, (iv) compare their results with the results from a coreference resolution tool (AllenNLP ${ }^{3}$ for English and Freeling ${ }^{4}$ for Spanish), and (v) discuss their conclusions on the forum.

The English class read The Domineering Eagle and the Inventive Bratling (Carryl, 1899), which uses the pronoun he to refer to the eagle; and the Spanish class read La lluvia de Verano (Hartzenbusch, 1948), which uses the pronoun ellas (they_fem.) as the subject of salvar (to save) to refer to niebla $y$ lluvia (fog and rain). We have chosen fables for this exercise because they are short authentic texts and have examples of personification, showing that sometimes it is possible (and even better for the context) to talk about something by using pronouns that usually refer to human entities.

Figure 5 presents the results from AllenNLP. In this tool, coreference chains are numbered and highlighted with different colours. Although the fables are written in verse, they were previously transformed into prose and the use of upper/lower case normalized to facilitate the automatic analysis. Learners could see that the tools still made some mistakes, for example, by starting a new coreference chain (number 4) instead of recognizing Bird of freedom as referring to the eagle, or by ignoring a large number of markeables (e.g. a small suburban borough). In view of these examples, students were invited to discuss the potentials and limitations of technology.

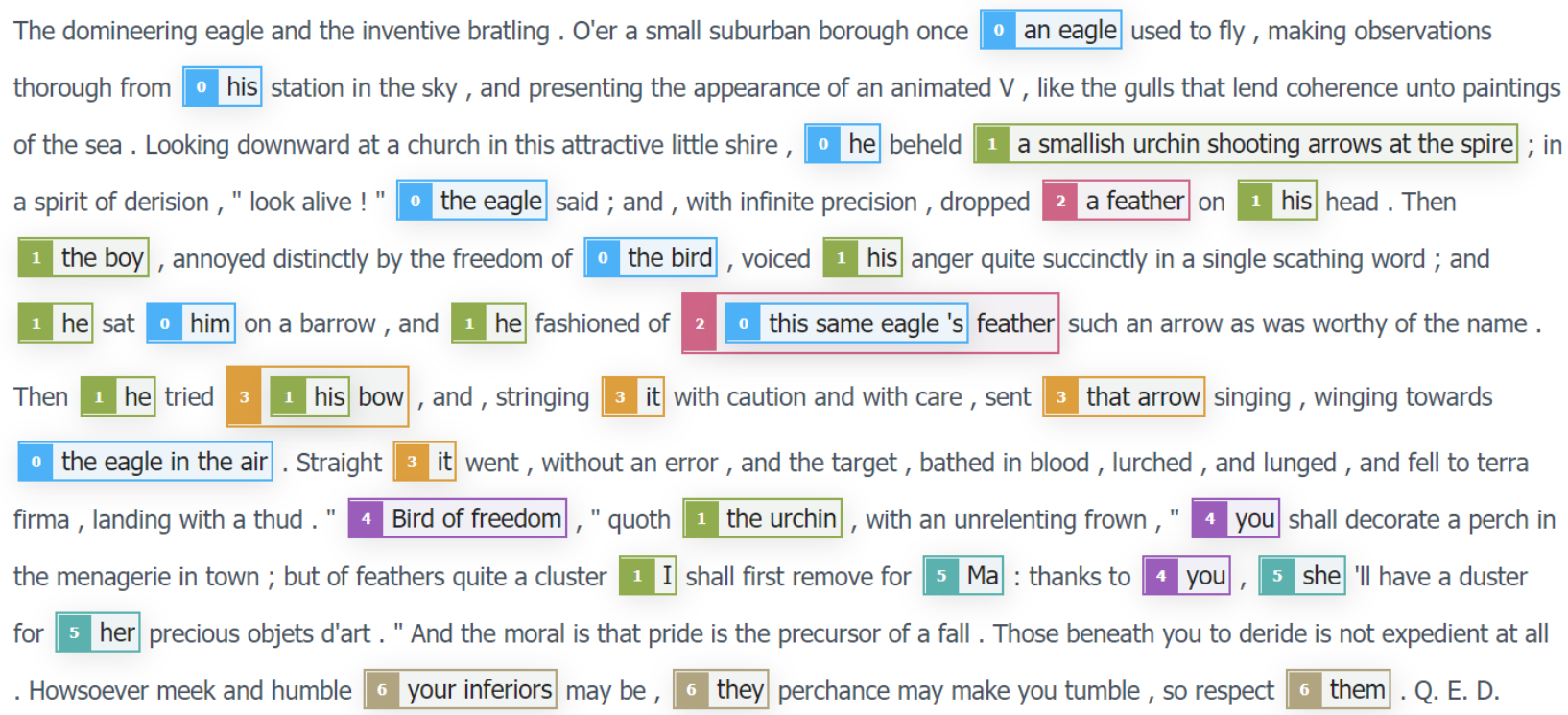

Figure 5. AllenNLP coreference resolution

Source: AllenNLP

Finally, the lesson ended with another activity like the one in the test, as explained before.

\footnotetext{
${ }^{3} \mathrm{https}: / /$ demo.allennlp.org/coreference-resolution

${ }^{4} \mathrm{http}: / /$ nlp.lsi.upc.edu/freeling/demo/demo.php
} 


\section{Discussion}

This paper presented the designing of an online course to teach anaphora in English and Spanish as foreign languages. The programme consisted of two lessons focused on this grammatical topic. Since learners were studying at university level to become language teachers or translators, it is relevant that they know the languages' grammar and linguistic terminology.

This learner-centred course used active methodologies to enhance learning. Each lesson had an activity using a language analysis tool (Sketch Engine, and AllenNLP or Freeling) that could be helpful to students in their future professions and that stimulated the debate on technology. There was also a great focus on communication and collaboration. Thus, for almost all activities, learners discussed with their peers on written forums.

There are many reasons to use technology in instruction. Some of them are to improve access to education, increase the quantity of materials and exercises, use technology tools that are relevant to students' careers, and make learning more student-centred (Diamond, 2011). In our view, it is important to let students be responsible for their learning process by stimulating their autonomy in classes. Moreover, this attitude may contribute to the learners' engagement and achievements.

The purpose of this paper was to discuss the designing of an online course on anaphora. In other articles, we have analysed students' learning outcomes (Bruscato \& Baptista, 2021b) and their anonymous evaluation of the classes (Bruscato \& Baptista, 2021a). Overall, the teaching module was evaluated positively and improved learners' comprehension of written texts.

The programme was designed to teach the basics of written anaphora in only two lessons with an heterogeneous class. Future work could extend the duration of the course and target other groups of learners. The course could also address anaphora in spoken texts (which may include analysing gestures, for example).

Although the target groups were Brazilian and Portuguese undergraduate students learning English or Spanish, instructors can adapt this course to other languages and groups of students. Based on their classes' results in a pre-test, they can plan the appropriate topics, texts, and activities.

The tools suggested here can be used for free and are available for many languages (Sketch Engine has corpora in more than 90 languages and Freeling reportedly analyses texts in 13 languages). Nevertheless, besides analysing the tools and properly introducing them to students, it is indispensable to guide them through the process. Still, it is important to use the available technology, especially in distance education, to enhance learners' autonomy and engagement in the lessons.

We hope to have contributed to the teaching of anaphora in foreign languages by showing how different types of activities, from more simple to more complex, can help students to better understand this discursive mechanism.

\section{References}

Bonwell, C. C., \& Eison, J. A. (1991). Active Learning: Creating Excitement in the Classroom. Washington: The George Washington University.

Boulton, A. (2010). Data-driven learning: Taking the computer out of the equation. Language learning, vol. 60, $\mathrm{n}$. 3, pp. 534-572.

Bruscato, A. M., \& Baptista, J. (2021a). Distance Learning of Anaphora in English and Spanish as Foreign Languages: Experience Report. In: Silva, H.; Uchôa, S.; Cabral, S. Língua Inglesa e Ensino Remoto: desafios e perspectivas. Cajazeiras - PB: IDEIA - Inst. De Desen. Educ. Interd. e Aprendizagem, 137-145. Available at: https://2da3ef0e-b3a2-4725-a7cf-19b6d57420dc.filesusr.com/ugd/976354_7625fe3f15a54892b688e94c39a915 $\underline{\mathrm{c} 0 . \mathrm{pdf}}$ 
Bruscato, A. M., \& Baptista, J. (2021b). Synchronous and Asynchronous Distance Learning of Anaphora in Foreign Languages: An Experimental Study. Texto Livre: Linguagem e Tecnologia, 14(1), 1-18. https://doi.org/10.35699/1983-3652.2021.29177

Bruscato, A. M., \& Baptista, J. (2021c). The Study of Anaphora in English and Spanish as Foreign Languages. Manuscript.

Carryl, G. (1899). The Domineering Eagle and the Inventive Bratling. In: Carryl, Guy Wetmore. Fables for the Frivolous. Harper \& Brothers. Available at: http://www.gutenberg.org/files/6438/6438-h/6438-h.htm\#5

Chomsky, N. (1981). Lectures on government and binding. Dordrecht: Foris.

Diamond, R. M. (2011). Designing and Assessing Courses and Curricula: A practical guide. San Francisco: John Wiley \& Sons.

Gardelle, L. (2012). Anaphora, anaphor and antecedent in nominal anaphora: Definitions and theoretical implications. Cercles, vol. 22, pp. 25-40.

Graves, K. (2000). Designing language courses: A guide for teachers. Boston: Heinle \& Heinle.

Halliday, M., \& Hasan, R. (1976). Cohesion in English. London: Longman.

Hartzenbusch, J. (1948). La lluvia de Verano. In: Hartzenbusch, Juan Eugenio. Fábulas en verso castellano. Madrid: Imprenta de la sociedad de operarios, pp. 69-72. Available at: http://www.cervantesvirtual.com/obravisor/fabulas-en-verso-castellano--1/html/fee57c5c-82b1-11df-acc7-002185ce6064_2.html\#I_23

Johns, T. (1991). Should you be persuaded: Two samples of data-driven learning materials. Birmingham: University of Birmingham.

Li, L. (2014). Computer-assisted vs. classroom instruction on developing reference tracking skills in L2 Chinese. Engaging language learners through technology integration: Theory, applications, and outcomes. IGI Global, pp. 72-96.

Marinoni, G., Van't Land, H., \& Jensen, T. (2020). The impact of Covid-19 on higher education around the world. IAU Global Survey Report.

Offir, B., Lev, Y., \& Bezalel, R. (2008). Surface and deep learning processes in distance education: Synchronous versus asynchronous systems. Computers \& Education, vol. 51, n. 3, pp. 1172-1183.

Perales, S., \& Mayorga, M. R. P. (2007). Sobre las propiedades referenciales de los sujetos nulos y pronominales del español oral y escrito. Las destrezas orales en la enseñanza del español L2-LE: XVII Congreso Internacional de la Asociación del Español como lengua extranjera (ASELE). Logroño, Spain, pp. 889-900.

Richards, J. C. (2013). Curriculum approaches in language teaching: Forward, central, and backward design. Relc Journal, vol. 44, pp. 5-33.

Schwartz, T. (2010). The Way We're Working Isn't Working: The four forgotten needs that energize great performance. New York: Simon and Schuster. 